\title{
A ciência e a tecnologia na TV brasileira: uma análise da programação da TV Globo
}

\author{
Vanessa Brasil de Carvalho \\ Luisa Massarani \\ Marina Ramalho \\ Luis Amorim \\ Maria Ataide Malcher \\ Rosicler Neves
}

Resumo: Neste estudo, analisamos como temas de C\&T são veiculados na emissora de TV aberta de maior audiência no Brasil, a TV Globo. Gravamos e analisamos uma amostra de duas semanas construídas (14 dias), representativas de um período de seis meses de 2013, totalizando 336 horas assistidas na íntegra. Pela análise de conteúdo, observamos que a ciência esteve presente em $7,3 \%$ da programação da emissora no período analisado e perpassou por várias categorias televisivas, desde telejornais a publicidades, de telenovelas a talk shows. A ciência esteve ligada, em grande medida, a questões de Medicina e Saúde. Cientistas e especialistas foram fontes de informações importantes sobre tais assuntos, assim como os cidadãos. Contudo, foi reduzida a presença da figura do cientista nas peças - e, quando presente, havia mais homens do que mulheres cientistas. As publicidades foram a categoria televisiva mais frequente em nosso corpus e, nelas, a ciência foi utilizada como um recurso para dar credibilidade ao produto, evidenciando o papel legitimador da ciência.

Palavras-chave: divulgação científica; ciência na TV; TV Globo.

Abstract: Science and Technology in Brazilian TV: an analysis of Globo TV programing - In this paper, we analyze how S\&T issues appears on the TV Globo, the channel with the largest audience in Brazil. The methodology of "constructed week" was used to compose a sample of two weeks (14 days), representative of six months in 2013. We recorded and watched each day, a total of 336 hours. Through a content analysis, we found out that science appeared in $7.3 \%$ of TV Globo broadcast during the period analyzed and was in several television categories, from TV news to advertising, from soap operas to talk shows. Science was more related to issues of Medicine and Health. Scientists and experts were important sources of information, 
but citizens were heard about these issues as well. However, we found out that scientists were less represented on TV - and, when they appeared, there were more men than women scientists. In advertising, the most frequent television category in our corpus, science was used as a way to enforce credibility to the product, highlighting the social role of science.

Key words: communication sciences; science in TV; TV Globo.

\section{Introdução}

A televisão foi implantada no Brasil em 1950 e, décadas depois, consolidou-se como o principal meio de comunicação da sociedade brasileira. Durante os primeiros anos dessa tecnologia no país, o aparelho era um bem de luxo, inacessível para a população de menor poder aquisitivo, mas o cenário começou a mudar na década de 1960 (ORTIZ, 2011). Atualmente, a TV é um "elemento central na integração imaginária do país e polo articulador da imagem que o país produz sobre si mesmo", de acordo com Reimão (2000, p. 60). A autora destaca que a programação televisiva é responsável pelo compartilhamento de informações e referências sobre o mundo no território brasileiro como um todo, interligando o país de uma forma inédita em nossa história. Esse meio de comunicação de massa está presente em 97,2\% dos domicílios brasileiros, segundo o Instituto Brasileiro de Geografia e Estatística (IBGE, 2013).

A TV ganha ainda mais relevância para este estudo por ser uma das principais fontes de informações sobre temas de ciência e tecnologia (C\&T), nos Estados Unidos (NATIONAL SCIENCE FOUNDATION, 2012), em países europeus (EUROPEAN COMMISSION, 2007) e em países da América Latina. Enquete nacional realizada no Brasil pelo Ministério da Ciência, Tecnologia e Inovação e pelo Museu da Vida (2010) mostrou que 71,0\% da população brasileira afirmam buscar informações em C\&T nesse meio de comunicação. Na Argentina, mais de um terço dos entrevistados afirma assistir a programas televisivos sobre questões científicas com certa frequência (MINCYT, 2014).

Alguns estudos sobre a veiculação de temas de C\&T na televisão se referem a programações específicas. No cenário europeu, León (2008) se dedicou a analisar a programação televisiva veiculada especificamente no horário nobre. Na Colômbia, Torres (2013) estudou a ciência em comerciais televisivos. No Brasil, Barca (1999) e Ramalho, Polino, Massarani (2012) analisaram as notícias sobre C\&T em telejornais; Massarani, Moreira (2002) e Guerra (2004) examinaram materiais de teledramaturgia; Siqueira, (1998), Rondelli (2004) e Medeiros e colaboradores (2013), programas de variedades. Contudo, ainda são reduzidos os estudos sobre a programação televisiva relacionada a C\&T de uma maneira mais ampla no país. Desse modo, há uma demanda por estudos que forneçam um mapeamento geral de como a C\&T se insere na TV, nos seus distintos gêneros televisivos, em particular no contexto latino-americano. 
Portanto, nosso estudo ${ }^{1}$ tem como objetivo apresentar a programação relacionada a C\&T da emissora de televisão aberta brasileira de maior audiência no Brasil.

\section{Metodologia}

Nosso objeto de estudo é a programação da Rede Globo de Televisão, que cobre 98,4\% do território nacional, atingindo 5.482 municípios e 99,5\% da população brasileira (REDE GLOBO, 2013). Essa emissora foi escolhida porque, como mencionado anteriormente, é a de maior audiência no país (DONOS DA MÍDIA, 2013). A TV Globo foi criada em 1965 na cidade do Rio de Janeiro. O grupo que dirige a emissora, conhecido como as Organizações Globo, também atua em outros ramos da comunicação, como jornais, revistas, emissoras de rádio, TV por assinatura, empresas de distribuição de conteúdo e informação, controlando, ao todo, 340 veículos de comunicação, incluindo suas afiliadas (MATTOS, 2010; DONOS DA MÍDIA, 2013).

A emissora transmite o seu sinal nacionalmente, entretanto, uma pequena parte da grade de programação é voltada para assuntos locais - como é o caso de alguns telejornais. Neste estudo, a programação analisada foi veiculada na cidade do Rio de Janeiro, onde se localiza a sede da TV Globo no Brasil.

Para estudar a programação relacionada a C\&T da emissora, analisamos uma amostra de duas semanas construídas² ${ }^{2}$, em um total de 14 dias, representativos de um período de seis meses (junho a novembro de 2013). Para compor as semanas construídas, sorteamos aleatoriamente, no período considerado, duas segundas-feiras, duas terças-feiras, duas quartas-feiras, e assim sucessivamente, até termos duas vezes cada dia da semana. Ao todo, foram 336 horas gravadas e assistidas na íntegra nas seguintes datas:

\begin{tabular}{|c|c|c|}
\hline Domingo & 22 de setembro & 29 de setembro \\
\hline Segunda-feira & 19 de agosto & 16 de setembro \\
\hline Terça-feira & 18 de junho & 29 de outubro \\
\hline Quarta-feira & 18 de setembro & 13 de novembro \\
\hline Quinta-feira & 12 de setembro & 24 de outubro \\
\hline Sexta-feira & 04 de outubro & 29 de novembro \\
\hline Sábado & 31 de agosto & 14 de setembro \\
\hline
\end{tabular}

Tab. 1. Datas sorteadas para compor a amostra da pesquisa

1 Este estudo integra um projeto mais amplo, apoiado pelo CNPq e Faperj realizado em colaboração com quatro instituições brasileiras (Fundação Oswaldo Cruz, Universidade de São Paulo e Universidades Federais do Pará e de Minas Gerais), do qual apresentamos um recorte referente aos dados coletados no Rio de Janeiro.

2 É uma metodologia utilizada em estudos de mídia, como em Ramalho (2013) eTorres (2013), que consiste na construção de uma amostra semanal a partir da seleção aleatória (por sorteio) de dias da semana durante um determinado período. Tal metodologia permite a construção de uma amostra estratificada que diminui significativamente o tamanho do universo de análise, mantendo-se, no entanto, a representatividade em relação ao todo. 
Esse recorte de análise se apresenta como um diferencial em relação aos demais estudos mencionados acima, pois consideramos a totalidade da programação de uma emissora brasileira durante as 24 horas de cada dia analisado. Em outras palavras, analisamos as diversas categorias e gêneros televisivos (ARONCHI, 2004) veiculados nesses dias, incluindo filmes, desenhos animados, séries, novelas, programas educativos, programas de variedades, telejornais e publicidades - ao contrário de outros estudos que se dedicam a horários ou gêneros televisivos específicos.

Em razão da amplitude e da diversidade do material gravado, encontramos dois desafios na pesquisa. O primeiro deles foi construir critérios que respaldassem a seleção de materiais das várias categorias televisivas relacionados a C\&T para serem incluídos no corpus. Tais critérios se basearam no protocolo da Rede Ibero-americana de Monitoramento e Capacitação em Jornalismo Científico (MASSARANI, RAMALHO, 2012), associado a Rondelli (2004) e Trench (2003). São eles:

- Menção direta a $C \& T$ : citação às palavras ciência, tecnologia, cientistas, pesquisa, pesquisadores, instituições de pesquisa, universidades (desde que relacionadas à produção científica). Menção a métodos ou processos científicos, apresentação de resultados de pesquisas ou produtos desenvolvidos cientificamente, assim como assuntos relacionados à política de Ciência \& Tecnologia (C\&T).

- Menção a dados e termos científicos: Menção a dados ou termos atribuídos à comunidade científica ou a um determinado ramo do conhecimento, mesmo que não sejam proferidos por cientistas. Consideramos como dados científicos informações e/ou reflexões que não podem ser oriundas do senso comum. Os termos científicos são caracterizados por palavras ou um conjunto delas que não se encaixam no vocabulário do cotidiano, no senso comum, sendo atribuídos à pesquisa científica.

- Presença de ilustração e/ou animações: inserção de peças que apresentam algum tipo de ilustração e /ou animação contendo informações científicas ou baseadas nelas, podendo ser uma explicação de um fato, um procedimento científico ou um exemplo da realidade.

- Material de divulgação científica: compreendem-se programações televisivas voltadas para o público amplo e/ou leigo com temáticas científicas e/ou voltadas para a popularização da ciência.

O segundo desafio foi desenvolver um protocolo de análise que fosse adequado para os diversos tipos de unidades de análise, em um estudo que perpassa a diversidade de gêneros da programação televisiva. Para tanto, também tomamos como base a ferramenta desenvolvida pela Rede Ibero-americana de Monitoramento e Capacitação em Jornalismo Científico, com algumas adaptações. 
Nosso protocolo é composto por sete eixos de análise, dos quais escolhemos para ser foco deste artigo: características gerais da peça ${ }^{3}$; temas abordados; características de formato e conteúdo; presença (ou não) de cientistas na peça; atores envolvidos.

\section{Resultados}

Ao todo, identificamos 619 peças veiculadas que continham pelo menos um dos critérios necessários para fazer parte de nosso corpus de análise (figura 1).

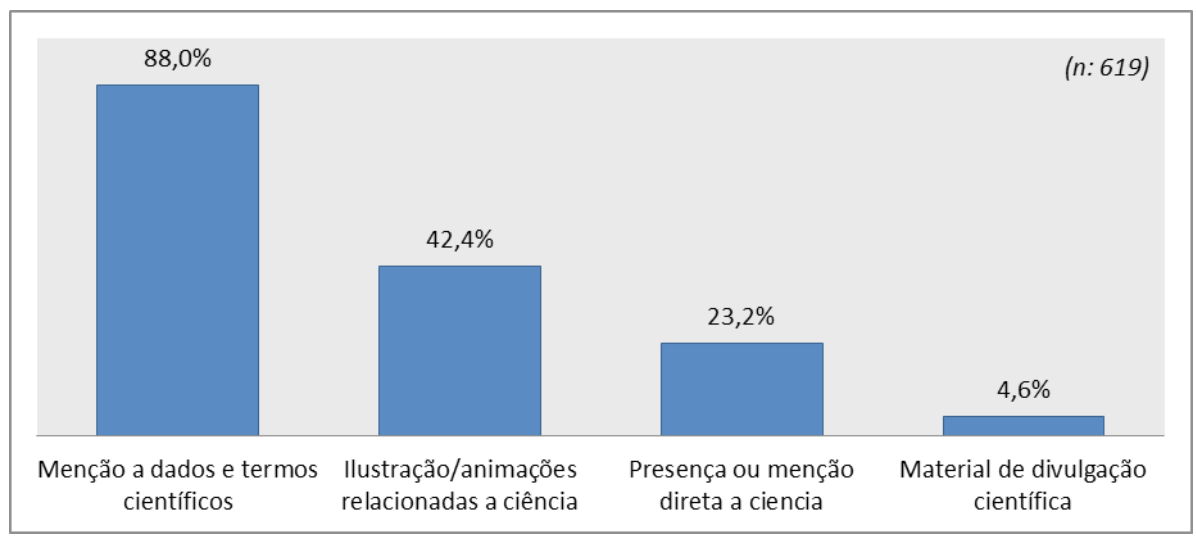

Fig.1. Porcentagem do total de peças veiculadas pela Rede Globo relacionadas a C\& $\mathrm{T}^{4}$

A menção a dados e termos científicos foi o critério mais presente para inclusão da peça em nosso corpus, estando em $88 \%$ dos materiais veiculados pela emissora (545 peças). Já as ilustrações e/ou animações relacionadas a C\&T estavam presentes em 42,4\% das peças selecionadas para análise (263 peças). A menção direta a C\&T foi identificada em apenas $23,2 \%$ do corpus (144 peças). As programações voltadas para a divulgação científica tiveram presença mais reduzida, de apenas $4,6 \%$ dos casos (29 peças).

A soma de todas as peças em nosso corpus chega a 24 horas, 19 minutos e 44 segundos. Portanto, das 336 horas de programação assistidas, cerca de 7,3\% do tempo estão relacionados a $C \& T$. As peças identificadas tiveram uma presença em alguma medida constante durante a semana (entre 78 e 107 peças por dia), exceto aos domingos, quando houve uma menor quantidade de peças registradas (56 peças). Nos domingos, a TV Globo apresenta uma grade de programação com bastante espaço destinado

3 Por peça, consideramos: reportagens jornalísticas; entrevistas; quadros temáticos de programas; cenas de telenovelas, de séries, de minisséries, de filmes e de desenhos; peças publicitárias; e merchandising em programas de variedades. É importante ressaltar que não consideramos como uma peça um programa inteiro. Em cada tipo de programação, foram recortadas apenas as partes ou cenas nas quais identificamos pelo menos um dos critérios estabelecidos.

4 Uma mesma matéria poderia estar relacionada a mais de um critério. Portanto, a soma dos percentuais é superior a $100 \%$. 
aos esportes, com transmissões de corridas de Fórmula 1, programas musicais e de auditório. Esses fatores podem ser uma das razões para a menor quantidade de peças relacionada a C\&T registrada nesse dia da semana.

Identificamos as categorias televisivas de acordo com os conceitos de Aronchi (2004), que trabalha com cinco categorias televisivas (tabela II): entretenimento, informação, educação, publicidade e outros. Cada categoria abrange vários gêneros que, por sua vez, são entendidos como "estratégias de comunicabilidade, fatos culturais e modelos dinâmicos" articulados com uma visão histórica do seu espaço de produção (ARONCHI, 2004, p. 44).

\begin{tabular}{|l|l|}
\hline \multicolumn{1}{|c|}{ Categoria } & \multicolumn{1}{c|}{ Gênero } \\
\hline Entretenimento & $\begin{array}{l}\text { Auditório - Colunismo social - Culinário - Desenho animado - Docudrama - } \\
\text { Esportivo - Filme - Game show - Humorístico - Interativo - Infantil - Musical } \\
- \text { Novela - Quiz show - Reality show - Revista - Série - Séria brasileira - Sitcom } \\
- \text { Talk show - Variedades - Western }\end{array}$ \\
\hline Informação & Debate - Documentário - Entrevista - Telejornal \\
\hline Educação & Educativo - Instrutivo \\
\hline Publicidade & Chamada - Filme comercial - Político - Sorteio - Telecompra - Merchandising \\
\hline Outros & Especial - Eventos - Religioso \\
\hline
\end{tabular}

Tab.2. Adaptação das categorias e gêneros televisivos identificados na programação da TV Globo 5

Na figura 2, mostramos a distribuição das peças registradas na TV Globo, de acordo com as categorias televisivas.

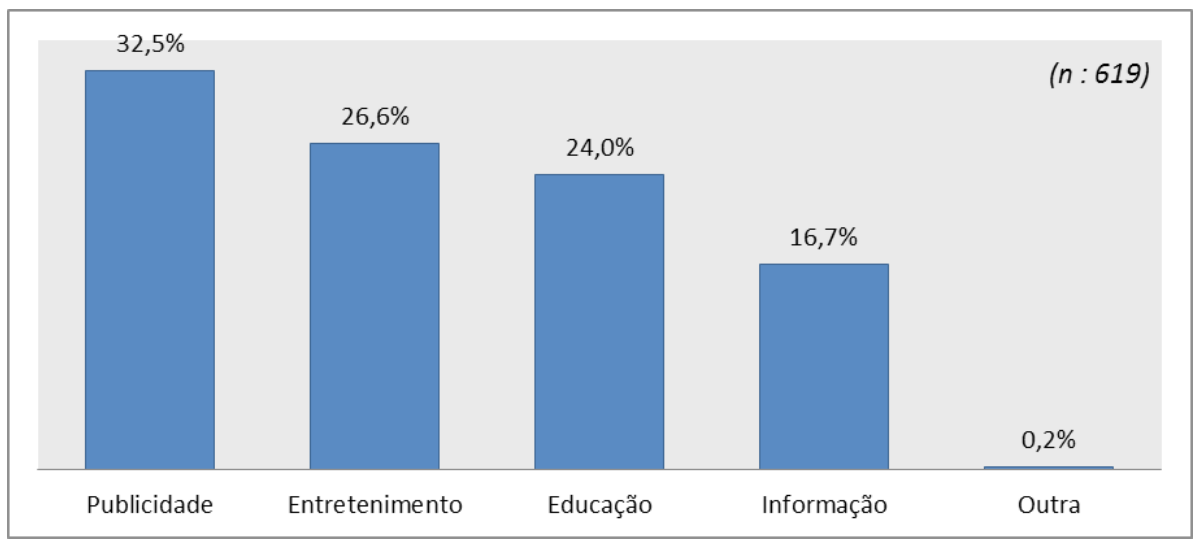

Fig.2. Porcentagem do total de peças relacionadas a C\&T da Rede Globo distribuídas por categorias televisivas.

A publicidade foi a categoria televisiva mais frequente em nosso corpus: 201 peças (32,5\% das peças da Globo) eram filmes comerciais (propagandas). A citação a dados

5 O quadro original de Aronchi (2004) incluía o gênero "Teledramaturgia" na Categoria "Entretenimento". Em nosso estudo, optamos por desconsiderar esse gênero por se sobrepor a outros, como Série, Série Brasileira e Novela. 
e/ou termos científicos, supostamente atestando a credibilidade dos produtos, foi recorrente nessa categoria televisiva.

Os programas de entretenimento com conteúdos científicos também foram recorrentes (165 peças), principalmente aqueles do gênero de variedades (113 peças, 18,3\%). Também identificamos, embora com presença baixa, revistas (15 peças, 2,4\%), programas esportivos $(0,6 \%)$, programas de auditório $(0,5 \%)$, talk shows $(0,5 \%)$ e programas musicais $(0,2 \%)$ com temáticas científicas. Os materiais de dramaturgia relacionados a temas de C\&T estiveram pouco presentes. Ainda assim, registramos cenas de novelas (12 peças, 1,9\%), desenhos animados (10 peças, 1,6\%), filmes ( 2 peças, 0,3\%) e séries ( 2 peças, $0,3 \%$ ).

Na categoria Educação, Aronchi (2004) engloba dois gêneros televisivos, o instrutivo e o educativo. O primeiro se caracteriza por programações voltadas para a formação técnica das pessoas, trazendo temas de especialidades administrativas, questões jurídicas e engenharias, por exemplo. Esse gênero foi registrado em 76 peças (12,2\%). O gênero educativo, por sua vez, foi identificado em 73 peças $(11,8 \%)$. Ele se diferencia por apresentar programas voltados para formação educacional básica, apresentando questões sobre História, Geografia, Matemática e Química, por exemplo.

Os principais gêneros encontrados na categoria informação são o telejornal - o mais recorrente, com 82 peças $(13,2 \%)$, estando a C\&T presente em todos os telejornais da emissora - e documentário (20 peças, 3,2\%).

Na tabela abaixo, identificamos o tempo de duração das peças distribuídas pelas categorias televisivas encontradas.

\begin{tabular}{|l|c|c|c|c|}
\hline \multicolumn{1}{|c|}{ Categorias televisivas } & Entretenimento & Informação & Educação & Publicidade \\
\hline Menor duração das peças & $00: 00: 14$ & $00: 00: 11$ & $00: 00: 16$ & $00: 00: 08$ \\
\hline Maior duração das peças & $00: 43: 17$ & $00: 15: 37$ & $00: 11: 53$ & $00: 01: 00$ \\
\hline Média de duração das peças & $\sim 00: 21: 45$ & $00: 07: 54$ & $\sim 00: 06: 04$ & $00: 00: 34$ \\
\hline
\end{tabular}

Tab.3. Média do tempo de duração das peças analisadas de acordo com as categorias televisivas

Identificamos maior presença de peças relacionadas a temas de C\&T durante as madrugadas (00h00min01seg - 06h00min00seg) e as manhãs (06h00min01seg 12h00min00seg). Durante a madrugada, encontramos 225 peças (36,3\% do corpus) e, durante as manhãs, 201 peças (32,4\%). Esses valores são justificados, principalmente, por três tipos de programas veiculados de segunda à sexta-feira: os telejornais, os programas de variedades e os programas educativos. Durante a madrugada, é veiculado o Jornal da Globo, que trata das últimas notícias do dia anterior e apresenta as primeiras notícias do dia que se inicia, e o Globo Rural, veiculado um pouco antes das 6 horas e que trata de questões específicas da zona rural brasileira. 
Nesse horário, também se destacaram os materiais educativos, os chamados Telecursos: programas que oferecem escolaridade básica e técnica ao telespectador por meio de teleaulas (TELECURSO, 2015).

Pela manhã, identificamos peças em dois importantes telejornais matutinos da emissora: o Bom dia Brasil e o Bom dia Rio, que trazem informações respectivamente sobre o país e a cidade do Rio de Janeiro. Além disso, identificamos com frequência temas de C\&T nos programas matutinos Bem Estar e Encontro com Fátima Bernardes.

À tarde e à noite, registramos uma quantidade menor de peças relacionadas a C\&T (102 e 91 peças respectivamente, que correspondem a 16,5\% e 14,7\% do corpus). Nesses períodos, a programação da Rede Globo veicula principalmente produtos voltados para o entretenimento: são cinco telenovelas e um filme (pelo menos), de segunda à sexta-feira. Nesses gêneros televisivos, não foi comum identificarmos materiais relacionados a C\&T. Por outro lado, dois telejornais importantes da emissora são veiculados nessa faixa de horário e contribuíram com a presença de notícias sobre C\&T. São eles: o Jornal Nacional, o telejornal de maior audiência na TV brasileira, e o telejornal local da cidade do Rio de Janeiro, RJ TV $2^{\mathrm{a}}$ edição.

\section{Principais assuntos relacionados a C\&T}

Observamos uma predominância das questões de Medicina e Saúde na programação de C\&T analisada, cobrindo 40,2\% do material da Rede Globo (249 peças). As demais áreas do conhecimento tiveram uma participação mais reduzida (figura 3).

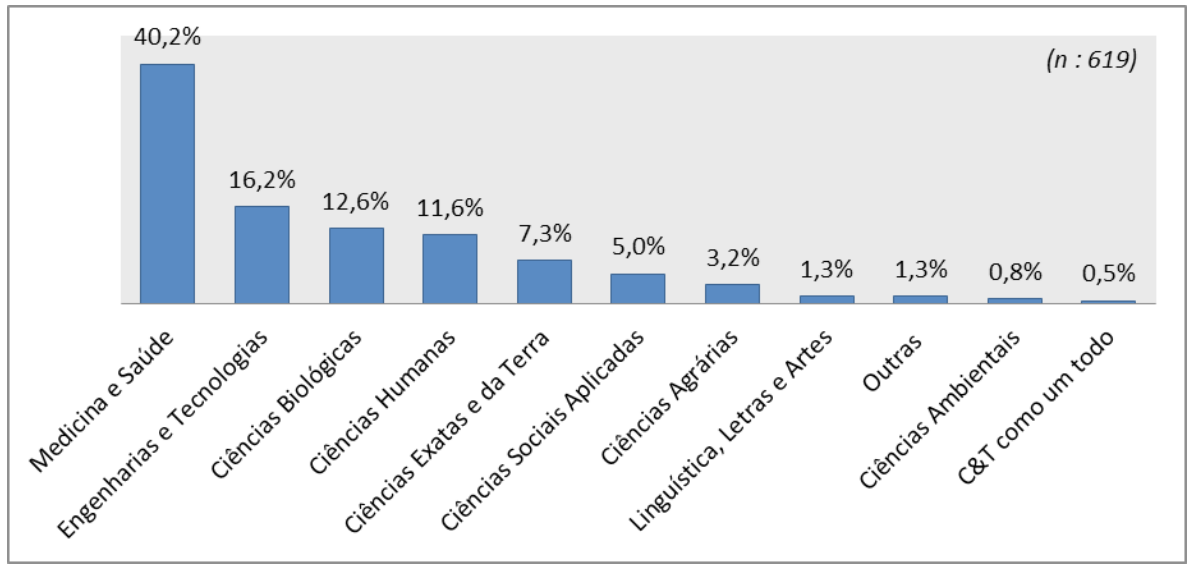

Fig. 3. Porcentagem do total de peças relacionadas a C\&T veiculadas pela Rede Globo, distribuídas por área do conhecimento.

Programações relacionadas a remédios, alimentação e produtos odontológicos foram temas comuns, todos vinculados a questões de Medicina e Saúde. As publicidades, 
em especial, contribuíram muito para a grande quantidade de peças relacionadas a essa área do conhecimento: $50,2 \%$ das peças relacionadas à temática eram dessa categoria televisiva.

A área de Ciências Biológicas também é marcada pela presença de materiais publicitários (57,6\% das peças relacionadas a essa área do conhecimento). Entre eles, citamos os produtos para cabelos e suplementos alimentares, quando enfocavam questões da biologia celular, bioquímicas e farmacológicas. Também registramos peças informativas relacionadas à fauna e flora.

A área de Ciências Exatas e da Terra foi identificada, em grande medida, em programas educativos (88,8\% das peças relacionadas a essa área do conhecimento) - assim como a área de Engenharias e Tecnologias (56,0\% das peças relacionadas a essa área) - que frequentemente abordaram processos aplicáveis à indústria. Além disso, foram recorrentes as publicidades voltadas para carros e combustíveis nas peças sobre Engenharias. Outros temas relacionados à área das Engenharias foram as inovações tecnológicas, especialmente automobilística, que surgiram em várias categorias televisivas: em reportagens dos telejornais, programas de entretenimento, publicidades e programas educativos.

As Ciências Humanas também estiveram muito presentes nos programas educativos (56,9\% das peças relacionadas a essa área do conhecimento), enquanto que as Ciências Sociais Aplicadas foram mais registradas em peças informativas $(61,2 \%$ das peças relacionadas a essa área do conhecimento).

As manifestações populares que aconteceram no Brasil em junho de 2013 foram tema recorrente de vários programas de variedades e de muitas matérias jornalísticas, já que alguns dos dias selecionados para a análise foram próximos a esses acontecimentos. Em sua maioria, foram categorizados como assuntos da área de Humanas ou Ciências Sociais Aplicadas, dependendo do tipo de discussão e/ou da formação do especialista ou cientista chamado para comentar o assunto. Temas de economia, política e cultura relacionados à ciência também foram incluídos nessas áreas.

As Ciências Agrárias estiveram basicamente presentes em programas informativos (95,0\% das peças relacionadas a essa área do conhecimento), em razão de sua inserção no Globo Rural (telejornal voltado para o público que vive e trabalha nas zonas rurais do país).

\section{Os cientistas na Rede Globo}

Identificamos que em todos os 619 itens havia a menção a, pelo menos, uma fonte de informação. Consideramos como fontes, pessoas, instituições ou grupos sociais que concederam informações sobre o assunto abordado na programação televisiva.

A figura do especialista foi a mais frequente como fonte de informação das peças, estando em $69,4 \%$ do corpus e sendo a principal fonte utilizada para tratar de temas científicos: trata-se de um profissional que é explicitamente apresentado como "especialista", que surge para dar informações sobre a sua área do conhecimento. 
Podia ser, por exemplo, um dentista que recomenda um determinado produto odontológico, um engenheiro que apresenta uma nova tecnologia ou um economista, que faz uma análise do comércio brasileiro no exterior.

Quando esses profissionais estavam explicitamente ligados a um estudo científico, eles foram considerados como cientistas. Também consideramos como cientistas as pessoas apresentadas com esse título ou sob a alcunha de pesquisadores. Esses profissionais estiveram presentes em cerca de um quarto das peças $(24,0 \%)$ e foram o terceiro grupo a ser utilizado como fonte com maior frequência. Outro dado importante foi a presença recorrente de falas dos cidadãos, que foram o segundo grupo de fontes mais comuns em nosso corpus. Ou seja, ao se falar de questões científicas, observamos que a programação da TV Globo apresentava, com regularidade, pessoas não especializadas para discutir os temas - e não só um grupo técnico-especializado de cientistas, especialistas ou médicos. Esses cidadãos deram testemunhos sobre o uso de produtos, técnicas ou até procedimentos relacionados a questões científicas.

Demos um destaque especial à figura dos cientistas pois observamos que, na maior parte das peças, eles apenas foram mencionados como fontes de informações e não tiveram a sua imagem veiculada nas programações. Neste contexto, observamos que foi reduzida a presença da figura do cientista na programação da emissora.

Das 619 peças selecionadas para análise, apenas 59 apresentavam a imagem propriamente dita do cientista, o que representa 9,5\% de todo o material da emissora. Do total de cientistas, 76 eram homens e 23, mulheres. Dos 76 homens, 57 eram brasileiros ( $75 \%$ dos homens cientistas identificados) e das 23 mulheres, apenas uma era estrangeira.

O local em que esses cientistas mais apareceram foi o laboratório, tanto homens $(51,3 \%)$ como mulheres $(73,9 \%)$. Homens e mulheres tiveram uma presença similar, percentualmente, em escritórios, coletivas de imprensa e trabalhos de campo (não mais que $10 \%$ cada um). Porém, os homens foram os únicos que estiveram presentes nos estúdios da emissora (19,7\% dos homens cientistas identificados).

A presença de ícones da ciência associados ao estereótipo de cientista foi marcante em nossa amostra: o jaleco esteve presente em 57,8\% dos homens cientistas e 91,3\% das mulheres cientistas; os óculos, em 47,3\% dos homens cientistas e 13\% das mulheres cientistas. Os computadores apareceram associados a 17,1\% dos homens cientistas e a $39,1 \%$ das mulheres cientistas. Poucos cientistas foram representados próximos a livros, papéis, luvas ou vidrarias e equipamentos técnicos (menos de 13\% cada um).

Tanto homens como mulheres cientistas estiveram mais presentes em programações voltadas para as Engenharias e Tecnologias (38,1\% dos homens cientistas e 47,8\% das mulheres cientistas). Os homens também se destacaram nas peças sobre as Ciências Humanas e Biológicas (14,5\% e 10,5\% dos homens cientistas), enquanto as mulheres foram vinculadas às áreas de C\&T como um todo (17,4\%), Medicina e Saúde (8,7\%) e Ciências Humanas $(8,7 \%)$. 


\section{Discussão e considerações finais}

Neste artigo, apresentamos um perfil geral da programação relacionada a C\&T veiculada no principal canal televisivo brasileiro. Um primeiro resultado importante é que temas de C\&T estão presentes em 7,3\% das horas transmitidas pela emissora no material analisado. Esse percentual ganha importância quando consideramos que a TV é o meio de comunicação mais abrangente em território brasileiro e que a programação da TV Globo chega à quase totalidade $(99,5 \%)$ da população brasileira (MATTOS, 2010; DONOS DA MÍDIA, 2013).

No entanto, esses percentuais referentes à presença da C\&T na TV devem ser vistos com cuidado. Identificamos poucas programações voltadas exclusivamente para divulgação científica: somente $4,6 \%$ de todo o material analisado neste estudo. Nas demais peças, a ciência poderia ser tanto o centro da programação televisiva, a exemplo de muitas reportagens identificadas, mas, também, poderia ser abordada de maneira tangencial, superficial ou estereotipada, como nos desenhos animados.

Um ponto que vale ser destacado é que nos programas de entretenimento, por exemplo, a ciência nem sempre foi o centro da discussão. Muitas vezes, os cientistas estavam ali para responder sobre um assunto do cotidiano - este sim o tema central do programa - em um espaço em que havia vários pontos de vista diferentes sobre o tema e a ciência era apenas uma das visões incluídas. Observamos esse tipo de presença do cientista na TV brasileira, a exemplo de outros analisados em nosso corpus, como uma maneira da ciência estar presente em várias discussões do dia-a-dia da população e não apenas como um tema de discussão relacionado às descobertas científicas mais recentes, normalmente veiculados em telejornais. Programações similares a essa descrita acima podem indicar que a ciência está presente nas discussões políticas e econômicas do país, é uma fonte de informação em debates diversos e está mais presente em materiais de entretenimento do que se poderia pensar a princípio.

Nos desenhos animados, também categorizados como entretenimento, observamos um padrão diferente. Quando eram apresentados cientistas, a ciência era o aspecto importante para o desenvolvimento da história contada. Além disso, havia uma reiteração do estereótipo do "cientista maluco", de jaleco branco, em um laboratório, descabelado, descolado da realidade e muitas vezes associado ao mal - o que já foi observado em outros estudos sobre esse tipo de programação (ROSA et al, 2005; MESQUITA, SOARES, 2008).

Já nas publicidades, que foram a categoria televisiva mais frequente em nosso corpus, a ciência foi utilizada como um recurso para legitimar e dar credibilidade ao produto. Foram recorrentes termos científicos, nomes técnicos de substâncias e animações que enfatizavam os efeitos "cientificamente comprovados" e/ou "recomendados por cientistas/ especialistas". Em outras palavras, embora a venda de produtos como xampus e cremes anti-acne (só para citar alguns) obviamente não estejam diretamente relacionados 
aos interesses da comunidade científica, o discurso científico aparece regularmente nas peças publicitárias desses produtos, evidenciando que a ciência e os cientistas são considerados autoridades confiáveis.

Torres (2013), em seu estudo sobre publicidades relacionadas a questões científicas na TV colombiana, também observa que a ciência foi utilizada como recurso retórico nas narrativas por ele analisadas. Isso se deve, segundo o autor, ao reconhecimento e à legitimidade social que a ciência ganhou com o público telespectador. Nesse sentido, nossos dados evidenciam que a ciência goza de legitimidade social similar no Brasil.

A programação televisiva brasileira dá ênfase às programações de entretenimento (REIMÃO, 2000), que foi a segunda categoria televisiva mais recorrente em nosso material. Essa categoria possui diversos gêneros relacionados à teledramaturgia e ficção, como telenovelas, filmes, seriados e desenhos animados. Se somarmos as peças desses gêneros, encontraremos 26 peças (4,2\% do corpus). Embora seja uma presença bastante reduzida em todo o material, se faz importante quando lembramos que a TV Globo é reconhecida nacional e internacionalmente por seus produtos de teledramaturgia, principalmente telenovelas (MATTOS, 2010; REIMÃO, 2000). Alguns autores, como Guerra (2004) e Massarani e Moreira (2002), identificaram e analisaram telenovelas da emissora que tiveram temáticas científicas no eixo central da narrativa. Esses autores sugerem que tratar de assuntos científicos em telenovelas tem o potencial de aproximar a ciência da sociedade, colocando temas científicos na conversa cotidiana de pessoas não especializadas.

Identificamos uma presença importante de peças relacionadas à ciência em telejornais, em consonância com estudos que se voltaram especificamente a este gênero de programa, a exemplo de Ramalho, Polino e Massarani (2012), que identificaram que 7,3\% das matérias do principal telejornal brasileiro, o Jornal Nacional, referem-se a C\&T. Em nosso estudo, identificamos a presença de temas de C\&T em todos os telejornais da Rede Globo distribuídos ao longo do dia, desde o telejornal voltado para assuntos da zona rural do país até o último jornal do dia, o Jornal da Globo, veiculado durante a madrugada.

A figura do cientista esteve pouco presente. Isso nos leva a refletir sobre como a ciência está sendo abordada pela emissora de maior audiência do país, já que o ator social mais importante da empreitada científica está ausente. Além disso, na maior parte das vezes, esses profissionais apareceram em seus laboratórios e vestidos de jalecos, o que sugere, em alguma medida, a reiteração do estereótipo do cientista, presente nos meios de comunicação de massa e no imaginário social (MEAD, METRAUX, 1957; LONG, BOIARSKY, THAYER, 2001; FLICKER, 2003; ROSA et al, 2005). Talvez a presença dos cientistas das áreas de Engenharias, Medicina e Ciências Biológicas tenha uma relação com esse tipo de caracterização do profissional, já que tais pesquisadores usam jalecos e trabalham em laboratórios usualmente. Assim, a programação televisiva reflete ao mesmo tempo em que reforça a imagem que se tem de um cientista, uma imagem estereotipada, mas também real. Talvez o que não seja tão claro nessa programação é mostrar a complexidade do trabalho desse profissional, que não se resume ao seu trabalho em laboratório. 
Assim, apresentamos um panorama da programação relacionada a C\&T na principal emissora brasileira de TV, a Rede Globo de Televisão. Observamos algumas características gerais e, acima de tudo, mostramos que, em termos quantitativos, a ciência está presente na programação televisiva. Contudo, nossos dados indicam a necessidade de aprofundarmos o estudo, adicionando outras ferramentas de análise, visando compreender melhor como a ciência é veiculada na televisão, assim como a sua recepção por parte das audiências.

Vanessa Brasil de Carvalho é doutoranda do Programa de Educação, Gestão e Difusão em Biociências, no Instituto de Bioquímica Médica Leopoldo de Meis da UFRJ e bolsista CAPES.

vanessabrasilcarvalho@gmail.com

Luisa Massarani é doutora pelo Programa de Educação, Gestão e Difusão em Biociências, no Instituto de Bioquímica Médica Leopoldo de Meis da UFRJ. É pesquisadora do Núcleo de Estudos da Divulgação Científica do Museu da Vida e coordenadora do Programa de Pós-Graduação em Divulgação da Ciência, Tecnologia e Saúde, ambos da Casa de Oswaldo Cruz, Fundação Oswaldo Cruz (Fiocruz). É bolsista produtividade do CNPq.

luisa.massarani4@gmail.com

Marina Ramalho é doutora pelo Programa de Educação, Gestão e Difusão em Biociências, no Instituto de Bioquímica Médica Leopoldo de Meis da UFRJ. É pesquisadora do Núcleo de Estudos da Divulgação Científica do Museu da Vida e professora do Programa de Pós-Graduação em Divulgação da Ciência, Tecnologia e Saúde, ambos da Casa de Oswaldo Cruz, Fundação Oswaldo Cruz (Fiocruz).

marina.fiocruz@gmail.com

Luis Amorim é mestre em Comunicação, Ciência e Mídia pela Fundação Oswaldo Cruz. É coordenador do Núcleo de Estudos da Divulgação Científica do Museu da Vida.

Iha2000@gmail.com 
Maria Ataide Malcher é doutora em Ciências da Comunicação pela USP. É professora do Programa de Pós-Graduação Comunicação, Cultura e Amazônia e da Faculdade de Comunicação da UFPA e do Programa de PósGraduação em Divulgação da Ciência, Tecnologia e Saúde da Casa de Oswaldo Cruz, Fundação Oswaldo Cruz (Fiocruz).

ataidemalcher@uol.com.br

Rosicler Neves é doutoranda do Programa de Educação, Gestão e Difusão em Biociências, no Instituto de Bioquímica Médica Leopoldo de Meis da Universidade Federal do Rio de Janeiro. Integra o Núcleo de Estudos da Divulgação Científica do Museu da Vida.

rosiclerneves3@gmail.com

\section{Referências}

ARONCHI, J. C. Gêneros e formatos na televisão brasileira. São Paulo: Summus, 2004.

BARCA, L. Ciência e comunicação na TV comercial: 14 anos do Programa Globo Ciência. Comunicação \& Educação. n 15, v. 81-86, mai/ago 1999.

DONOS DA MÍDIA. Disponível em: <www.donosdamidia.com.br>. Acesso em: 26 mar 2013.

EUROPEAN COMMISSION. Special Eurobarometer on scientific research in the media. 2007. Disponível em: <http://ec.europa.eu/public_opinion/archives/ebs/ebs_282_en.pdf.> Acesso em: 9 mai 2012.

FLICKER, E. Between Brains and Breasts - Women Scientists in Fiction Film: On the Marginalization and Sexualization of Scientific Competence. Public Understanding of Science. N. 12, pp. 307-318, 2003.

GUERRA, R. O Discurso Sobre a Ciência nas Telenovelas O Clone e Barriga de Aluguel. Dissertação (Mestrado em Comunicação) - Universidade Federal de Pernambuco (UFPE), Recife, 2004.

INSTITUTO BRASILEIRO DE GEOGRAFIA E ESTATÍSTICA. Pesquisa Nacional por Amostra de Domicílios Brasil e Síntese de Indicadores 2013. Disponível em: < http://www.ibge.gov.br/home/presidencia/ noticias/imprensa/ppts/00000018883109232014310419410583.pdf>. Acesso em: 18 nov 2014.

LEÓN, B. Science related information in European television: a study of prime-time news. Public Understanding of Science, v. 17, n. 4, p. 443-460, 2008.

LONG, M.; BOIARSKY, G.; THAYER, G. Gender and racial counter-stereotypes in science education television: a content analysis. Public Understanding of Science. v. 10, n. 3, p. 255-269, jul 2001.

MASSARANI, L.; MOREIRA, I. O clone. Public Understanding of Science, Londres, v. 11, n.2, p. 207-208, 2002.

MASSARANI, L.; RAMALHO, M. Monitoramento e capacitação em jornalismo científico: a experiência de uma rede ibero-americana. Rio de Janeiro: Museu da Vida / Casa de Oswaldo Cruz / Fiocruz: Centro Internacional de Estudios Superiores de Comunicación para América Latina (Ciespal), 2012.

MATTOS, S. História da televisão brasileira: uma visão econômica, social e política. Petróplis: Vozes. 5 ed. 2010.

MEAD, M.; METRAUX, R. Image of the Scientist among High-School Students: a pilot study. Science, n. 30, v. 126, p. 384-390, ago 1957. 
MEDEIROS, F. et al. Ciência e tecnologia em um programa de infotainment: uma análise de conteúdo da cobertura do Fantástico. Intercom: Revista Brasileira de Ciências da Comunicação, v. 36 , p. $127-147,2013$.

MESQUITA, N.; SOARES, M. Visões de ciência em desenhos animados: uma alternativa para o debate sobre a construção do conhecimento científico em sala de aula. Ciência \& Educação, v. 14, n. 3, p. 417-29, 2008.

MINCYT. La percepción de los argentinos sobre la investigación científica en el país. Tercera Encuesta Nacional (2012), Ciudad Autónoma de Buenos Aires, MinCyT, 2014.

MINISTÉRIO DA CIÊNCIA E TECNOLOGIA. MUSEU DA VIDA. Percepção Pública da Ciência e Tecnologia no Brasil. Brasília. 2010. Disponível em: <http://www.museudavida.fiocruz.br/media/ enquete2010.pdf>. Acesso em 8 nov 20124.

NATIONAL SCIENCE FOUNDATION. Science and technology: public attitudes and understanding. Science and Engineering Indicators 2012. 2012. Disponível em: <http://www.nsf.gov/statistics/ seind12/c7/c7h.htm>. Acesso em: 19 abr 2013.

ORTIZ, R. A moderna tradição brasileira. 5a edição. São Paulo: Brasiliense, 2001.

RAMALHO, M. A ciência no Jornal Nacional e na Percepção do Público. Tese (Doutorado em Química Biológica) - Universidade Federal do Rio de Janeiro, Rio de Janeiro, 2013.

RAMALHO, M.; POLINO, C.; MASSARANI, L. Do laboratório para o horário nobre: a cobertura de ciência no principal telejornal brasileiro. Journal of Science Communication, v. 11, p. 1-10, 2012.

REDE GLOBO. TV Globo e você. Disponível em: <http://redeglobo.globo.com/TVG/0,,9648,00. html>. Acesso em: 14 ago 2013.

REIMÃO, S. A televisão no Brasil - ontem e hoje. In: REIMÃO, S. Televisão na América Latina: 7 estudos. São Bernardo do Campo: Universidade Metodista de São Paulo, 2000, p. 59-80.

RONDELLI, D. R. R. A ciência no picadeiro: Uma análise das reportagens sobre ciência no programa Fantástico. Dissertação (Mestrado em Comunicação Social) - Universidade Metodista de São Paulo (UMESP), São Paulo 2004.

ROSA, M. I. P. et al. Os cientistas nos desenhos animados e os olhares das crianças. In: V ENCONTRO NACIONAL DE PESQUISA EM EDUCAÇÃO EM CIÊNCIAS, 2005, Bauru (SP). Anais, 2005

SIQUEIRA, D. Ciência na televisão: mito ritual e espetáculo. Dissertação (Mestrado em Informação) - Universidade Federal do Rio de Janeiro (UFRJ), Rio de Janeiro, 1998.

TELECURSO. O que é o telecurso? Disponível em: <http://educacao.globo.com/telecurso/ noticia/2014/11/o-que-e.html>. Acesso em: 29 mar 2015.

TORRES, H. Uso de la ciencia en la publicidade televisiva colombiana. Un estudio exploratorio sobre las representaciones de la ciencia em la televison. Universitas humanistica, n. 75, pp. 447475, janeiro-junho 2013.

TRENCH, B. Media Studies Module. The European Network of Science Communication Teachers. 2003.

Artigo recebido em agosto de 2015 e aprovado em maio de 2016.

\section{ERRATA}

No artigo <A ciência e a tecnologia na TV brasileira: uma análise da programação da TV Globo >, com número de DOI <http://dx.doi.org/10.1590/1982-25542016224238>, publicado no periódico <Galaxia>, n.33, pp.184 a 198,

ONDE SE LIA: o sobrenome da autora Maria Ataide Malher

LEIA-SE: Maria Ataide Malcher 